\title{
MONSTRUOS QUE SUSURRAN EN LOS RELATOS DE CLAUDIA HERNÁNDEZ
}

Hilda Gairaud Ruiz

\section{(c) $(7) \odot$}

Esta obra está bajo una licencia Creative Commons 



\title{
MONSTRUOS QUE SUSURRAN EN LOS RELATOS DE CLAUDIA HERNÁNDEZ
}

\author{
MONSTERS THAT WHISPER IN THE STORIES OF CLAUDIA \\ HERNANDEZ
}

\author{
Hilda Gairaud Ruiz
}

\begin{abstract}
RESUMEN
El tema del presente artículo es la representación de lo monstruoso en algunos textos literarios de la autora salvadoreña Claudia Hernández dentro del marco de la narrativa de posguerra. El objetivo principal es analizar la caracterización de algunos personajes que se nos presentan como monstruos: como seres amorfos, a veces invisibles e infames que, dentro de la estética en los cuentos, transgreden la concepción de personajes "normales" y "estéticos" al cotejarse con los marcos de los cánones establecidos. Para examinar lo monstruoso en la narrativa se utiliza el análisis interpretativo como método principal y la crítica literaria ya que estos métodos permiten hacer vinculaciones entre la literatura, historia, y la cultura. En la ficción, los personajes monstruosos aparecen como criaturas animalescas, especies endémicas, voces invisibles y fantasmas que seducen y susurran a otros personajes incitándolos a formar parte de los escenarios en que habitan: submundos ficticios y simbólicos, contextos inmundos y escatológicos. Figurativamente, estos personajes están relacionados a la otredad y a la degradación de la subjetividad salvadoreña debido a la violencia que ha predominado dentro del contexto de posguerra.

Palabras clave: monstruoso, subjetividad, degradación, otredad, violencia.
\end{abstract}

\begin{abstract}
The main topic of this article is the representation of the monstrous and hideous characters present in several literary texts written by the Salvadorian author Claudia Hernández within the frame of the postwar literature in Central America. The aim is to analyze the characterization of these personages which appear as amorphous beings, sometimes invisible and dreadful in the current aesthetics of the texts; mostly, if they are compared with "normal" characters present in established canons in literature. In order to examine the monsters in this type of narrative, the method of interpretative analysis will be used as well as literary criticism for these two methods allow a more accurate examination which intersect literature, history and culture in general. Monstrous characters are depicted as animalistic creatures, endemic species, invisible voices and apparitions that whisper and seduce other characters inciting them to become part of the scenarios that they inhabit: fictitious and symbolic underworlds and eschatological and filthy contexts. Figuratively, monstrous characters portray the representation of otherness and the degradation of the Salvadorian subjectivity due to the predominant state of violence present in the postwar period.
\end{abstract}

Key words: monstrous, subjectivity, degradation, otherness, violence.

\footnotetext{
Dra. Hilda Gairaud R. Universidad de Costa Rica. Profesora asociada de la Escuela de Lenguas Modernas. Costa Rica.

Correo electrónico: hgairaud@yahoo.com
}

Recepción: 20- 05- 2015

Aceptación: 19- 06- 2015 


\section{Introducción}

A pesar de la problematización en torno a la clasificación de textos literarios centroamericanos ya sea que se consideren textos de posguerra, posrevolucionarios y/o de posregionalismo (Mackenbach, 2004), en las últimas décadas del siglo XX, existe evidencia de un corpus literario asociado a diversos autores centroamericanos, como Manlio Argueta, Horacio Castellanos Moya, Franz Galich y Claudia Hernández, entre otros, cuya estética presenta ciertas temáticas y estrategias literarias convergentes que varios críticos, como Alexandra Ortiz (2002), Rafael Lara (1999), Anabella Acevedo (2000) y Beatriz Cortez (2010), han denominado literatura de posguerra.

Un común denominador que caracteriza esta literatura es la representación de la violencia en muchas de sus expresiones. A las manifestaciones de violencia física, estructural y cultural se añaden a otros tipos de violencia como los definidos recientemente por el activista político y erudito literario alemán Jean Phillip Reemtsma (2008), quien propone distintivas expresiones de violencia como la locativa, la captiva, la raptiva y la autotélica. ${ }^{1}$ Este último tipo expone el uso de la violencia como fin en sí misma: la violencia autotélica motiva a sus perpetradores a destruir a sus víctimas simplemente porque ellos tienen el poder de hacerlo (Reemmtsma, 2008, p. 139). Tanto los personajes, las tramas como el entorno ilustran subjetividades violentadas por el uso irracional del poder. Los personajes representan sujetos marginalizados y excluidos desarrollando sus experiencias de vida degradadas en escenarios abyectos, igualmente violentados.

El caso específico de la narrativa de Claudia Hernández, al que hace referencia la presente investigación, presenta estos escenarios vinculados a la representación, en la ficción, de imaginarios sociales marginales que a menudo muestran entrecruzamientos con la historia de El Salvador y los procesos militares-revolucionarios vividos en los enfrentamientos bélicos de la década de los 80. Las tramas en relatos ilustran un proceso en la historia de dicho país: la pérdida de fe en la revolución y en el liderazgo político mediante una sensibilidad llamada desencanto. Esta sensibilidad, según Beatriz Cortez (2010), mezcla los sentimientos de desilusión, frustración y desengaño que induce a los personajes en los cuentos a manifestarse con cinismo y con violencia. Según Cortez (2010), ya para la segunda mitad del siglo XX, la violencia está generalizada en el contexto y cambia el enfoque en la revolución para estar más relacionada con la criminalidad y la delincuencia. En el ámbito literario, Alexandra Ortiz (2008, p. 192) citando a Horacio Moya Castellanos indica que el discurso en el desencanto (re) inventa el rostro del otro (subalterno) salvadoreño, aquel que ya no es guerrillero, ni soldado pero que debe continuar con la necesidad de preservar la memoria de recordar a la nación que no debe olvidar. De esta forma, los textos literarios tienden a representar al otro subalterno dentro de una "estética extrema" comprometida con lo social (Ortiz-Wallner, 2008, p. 192).

Este tipo de estética extrema caracteriza la narrativa breve de Hernández cuando aborda la temática de la violencia. La utilización de una amalgama de estrategias que mezcla diversas modalidades literarias: destaca el empleo de un exacerbado simbolismo, un marcado uso de la figuratividad, de lo hiperbólico, de la ironía y del sarcasmo; el empleo de la dislocación y la fragmentación del tiempo y de la trama son algunos ejemplos de las formas con que el discurso narrativo refuerza la representación de la violencia. Sin embargo, la estética extrema que genera mayor impacto dentro de la narrativa es el empleo de lo fantástico en cuyo ámbito se ubica lo monstruoso. 
En la ficción de Hernández, los límites entre la dicotomía, lo real y lo fantástico (ámbito en donde se desarrollan los personajes monstruosos) se vuelven borrosos y constituyen un ejemplo de la arbitrariedad, flexibilidad y la difusión de las fronteras imaginarias en el discurso. Y es que no es casualidad que la autora nombrara uno de sus libros De Fronteras (2007b), puesto que en su narrativa puede visualizarse una intencionalidad discursiva de difuminar fronteras figurativas, físicas, simbólicas, imaginarias, temporales, espaciales y políticas, entre algunas otras. Estas fronteras representadas en los textos no se circunscriben a un tiempo determinado o a un espacio específico (Hernández, 2007a). Las líneas divisorias operan metafóricamente delimitando y, a la vez, extendiendo el espacio, el tiempo, las situaciones de las tramas y las subjetividades representadas en los personajes.

Es precisamente entre la frontera de lo real y lo fantástico en donde aparecen los personajes monstruos. En algunos relatos son seres amorfos y en otros, encarnan diversas formas, a veces son invisibles y solo se perciben mediante sus voces. Pero, en general, siempre se manifiestan presuntamente transgrediendo lo que se concibe "normal" y "estético" si se compara con los marcos de los cánones tradicionales establecidos. Por ejemplo, a algunos personajes en los relatos de Hernández los encarnan monstruos, criaturas animalescas, especies sui generis, voces espectrales que incitan a otros personajes a formar parte de un entorno degradado y escatológico. Los monstruos en algunos casos constituyen parte de una otredad expresada por una apariencia "antiestética" y un comportamiento bizarro y anormal que transgrede, distorsiona y degrada la concepción estandarizada de "lo estético" y el comportamiento "normal" del ser humano en sociedad. De muchas formas, al vincularse con la historia, estos personajes han sido relacionados a la degradación que ha sufrido la subjetividad salvadoreña debido a la violencia generalizada, en todas sus expresiones pero principalmente a la violencia autotélica, que es la que predomina en el contexto de posguerra.

\section{Los monstruos}

El monstruo y lo monstruoso en literatura ha sido teorizado por varios críticos. Para ilustrar, Georges Canguilhem (1976) afirma que el monstruo aparece cuando el orden se pone en duda y se frustra la confianza sólida en un orden establecido y apreciamos una diferencia morfológica, una apariencia de ambigüedad específica que él llama "un malogro morfológico". Según Canguilhem (1976), el monstruo representa a lo "otro", pertenece a un orden distinto al orden probable.

De manera similar, Foucault (2007) vincula a los monstruos a lo "anormal" y a la "otredad" pero también relaciona la concepción discursiva de lo monstruoso al poder y a lo abyecto. Foucault (2007) manifiesta en Los anormales, que por su apariencia y por sus prácticas sociales, algunos sujetos se apartan de los que se ha concebido como la normalidad, pero que resulta ser una normalidad protegida, según él, por un continuum, a través de un discurso que se ha envestido de verdad legitimado por la institucionalidad dentro del cuerpo social (él menciona la institucionalidad médica, legal e histórica). Estos discursos promueven discursos absolutos y definen lo que es anómalo, represivo y punitivo (Foucault, 2007, p. 19). Dentro de estas categorías mencionadas están encasillados los "anormales" o monstruos. Ellos son vistos de esta forma por quienes gozan de legitimidad en sociedad: son monstruos por poseer cuerpos diferentes y/o subjetividades que no siguen la normatividad. Por sus prácticas diferentes o inusuales son catalogados como seres "otros", marginalizados, degradados y 
excluidos. Estas condiciones explican una dinámica de funcionamiento del poder para Foucault (2003), hay quienes definen lo normal y sobre quienes recae lo que no es. El poder "funciona en red y [su] visibilidad no solo radica en la docilidad y la sumisión sobre los que se ejerce el poder [y se impone] el silencio" (Foucault, 2003, p. 39).

En adición, los monstruos también se asocian a lo abyecto. En este sentido, Julia Kristeva propone, en Poderes de la perversión (1982), las prácticas humanas de la expulsión y la represión dentro de la categoría que contempla lo abyecto. Kristeva (1982, p. 22) argumenta mediante una disertación sobre el objeto que "la imagen más o menos bella donde me miro o me reconozco se basa en una abyección que la fisura cuando se distiende la represión, [que constituye] su guardián permanente". Para uno transformarse en "yo", según Kristeva (1982, p. 24), entonces se debe renunciar a una parte de sí y debe observarse en su abyección: "Lo abyecto es la violencia del duelo de un 'objeto' desde siempre perdido". 2 Además ella señala que abyecto es "aquello que perturba una identidad, un sistema, un orden. Aquello que no respeta los límites, los lugares, las reglas, la complicidad, lo ambiguo, lo mixto" (1982, p. 11). El sujeto abyecto es un arrojado, un excluido, que se separa, que no reconoce las reglas del juego, y por lo tanto "erra en vez de reconocerse, de desear, de pertenecer o rechazar" (1982, p. 16). De esta forma, cuando un sujeto abyecto se distingue por su otredad, su exclusión de lo considerado "normal" y "estético", es que se le relaciona lo monstruoso.

La categoría de lo abyecto se sublima también en el discurso literario. Yansi Pérez (2012, p. 50) señala que el lugar y el papel de la esfera literaria dentro del periodo de la posguerra es un espacio privilegiado para negociar la memoria histórica y la reconstrucción de la identidad nacional en la región centroamericana. Dentro de este espacio, se propone lo abyecto como una estética que representa algunos tipos de las identidades y subjetividades otras, expulsadas, excluidas, rechazadas y "erradas" interactuando en estados y espacios vinculados a la violencia extrema heredada de las guerras civiles, así como el trauma que viven por estar afectadas durante la posguerra.

Lo monstruoso en el caso específico de la narrativa de Claudia Hernández, la presencia de los personajes monstruos ofrece interpretaciones ambivalentes y ambiguas que se ajustan parcial o cabalmente a las teorizaciones antes mencionadas debido a su alto nivel de representación simbólica. Un grupo de monstruos en algunos cuentos está directamente relacionado a la violencia sistematizada que ejercen los personajes que representan al poder y la legitimidad cultural tal como teorizan Canguilhem (1976) y Foucault (2007) en Los anormales. Este grupo empoderado violenta a personajes considerados "otros", marginalizados, excluidos y subalternos que, a la vez, dentro de otro grupo de relatos, constituye otro conjunto de monstruos. Estos últimos encarnan monstruos que representan lo marginal y subalterno. Y son catalogados así (como monstruos) por quienes gozan de legitimidad en sociedad: para ellos los marginalizados y los excluidos desencajan en el imaginario y se salen de lo que se ha concebido discursivamente como normal. Este tipo de monstruos lo constituyen los personajes "otros" presuntamente anómalos o defectuosos debido a su apariencia fenotípica y/o a sus conductas. Son seres abyectos según los sujetos que defienden los discursos absolutos de verdad.

Este último grupo de personajes monstruos abyectos son el objeto de estudio de esta disertación. Estos personajes están presentes en tres cuentos del libro La canción del mar (Hernández, 2007a): "El cerco de las acacias", "Un nombre que es la oscuridad” y "El bar de la calle Hudson". En estos relatos específicos, los personajes califican como monstruos no solo por la descripción anormal de su apariencia sino también por sus acciones: principalmente 
porque son seres que con sus voces, inaudibles para algunos pero claras para otros, seducen, susurrando a los oídos de sus víctimas, invitándolos y conduciéndolos a transitar por donde no se debe. Este presunto acto de transgresión conduce a las víctimas a perderse en lugares oscuros e inhóspitos que les permite conocer lo que está prohibido, aquello que dentro del imaginario creado en el cuento, está vedado por ser supuestamente pernicioso. No obstante, estos actos de transgresión adquieren un valor ambivalente puesto que el personaje al traspasar los límites de lo considerado bueno y lo malo, de lo permitido y lo prohibido, adquiere el conocimiento necesario e ineludible de la dualidad del ser humano, de las cosas, de la experiencia y de la existencia. Los cuentos sugieren la necesidad de conocer las "dos caras de una moneda"; es decir, el dualismo, el dimorfismo, la ambivalencia y las contradicciones que coexisten dentro del marco de la experiencia humana.

En el relato "El cerco de las acacias" (Hernández, 2007a, p. 8), un hombre de "dientes roídos y el cabello blanqueado por el viento del "Tánger” (ciudad mítica elogiada históricamente por la belleza de sus paisajes, así como por la hermosura de sus habitantes, los primitivos nativos de Tingis) invita a un niño a conocer a los monstruos que habitan en su jardín: "tres aladas criaturas de cuatro patas y arrugados rostros [y cuerpos oscuros] que se posaban sobre las ramas" de un cerco de acacias. Estas criaturas hablaban al niño, le enseñaban sobre "historias del mundo y sus pueblos" y contestaban sus preguntas distrayéndolo de sus asignaciones y asumiendo el significativo papel de padres y maestros. Sin embargo, cuando enseñaban al niño "esparcían por el lugar un penetrante olor similar al de los nidos de las serpientes" (Hernández, 2007, p. 8). El relato presenta a estos personajes en forma ambivalente: aunque las imágenes visuales de estas criaturas son monstruosas y la imagen olfativa es pútrida y se asocia a lo abyecto y repulsivo y, a pesar de que las voces que "mal" aconsejan al niño lo hacen desde un referente simbólico de un asidero de maldad (un nido de serpientes), del texto también se puede interpretar que la exposición del niño a estos "monstruos" es necesaria y hasta saludable. Según Jean Chevalier (1995) la simbología de la serpiente está asociada tanto a la vida como a la muerte. La serpiente, al ocultarse en agujeros y en la oscuridad, es símbolo de lo terrenal, del mundo subterráneo y el reino de los muertos; y por su capacidad de "mudar" de piel, es ambiguamente símbolo del rejuvenecimiento. Además de asociarse a serpientes y a la muerte, al ser los monstruos criaturas aladas que pueden volar, estas se relacionan, de forma contrastante, a entes encargados de las relaciones entre cielo y tierra, a criaturas mensajeras del cielo, y, por su nombre en griego, son también sinónimos de presagio, personajes que se asocian a ángeles y a estados espirituales y superiores del ser (Chevalier, 1995).

Por lo anterior, el texto sugiere que el conocimiento que estas criaturas monstruosas dan al niño, encierra interpretaciones duales y ambiguas: por una parte es un conocimiento vinculado a lo "anormal", lo "abyecto", a lo que se escapa de la regla y que podría percibirse como mal o maldad; y por otro, es también un conocimiento necesario y trascendente ya que revela información de reinos, mundos terrenales y divinos, de la experiencia física y espiritual. Las criaturas invitan al niño a conocer realidades "otras" que pueden descoyuntarse de la norma y normatividad (el discurso legitimado y envestido de verdad) y parecer "monstruosas" para quienes se consideran "normales" pero que, asimismo, le dan una consciencia y un entendimiento necesario de materialidades que son parte de la existencia humana. En otras palabras, le dan al niño una sabiduría de otros tipos de existencia.

Además, estos monstruos habitan en un cerco de acacias, árboles que tienen la característica particular de poseer un sistema de defensa que cuando son abordados por un 
depredador reaccionan liberando sustancias tóxicas y mortales desde su follaje para protegerse (Christie, 2014). Esta condición está representada en el relato cuando, al ver la madre el peligro que significan las criaturas en la arboleda de acacias, la manda a cortar pero no la puede desaparecer, puesto que, al finalizar el cuento, el niño siempre acude al llamado de las voces que lo seducen desde "las ramas de unos árboles invisibles que ella [la madre nunca pudo] derribar” (Hernández, 2007a, p. 8).

De las apreciaciones anteriores se puede interpretar que los monstruos en las acacias simbolizan la existencia ineludible e indispensable, dentro del marco de la condición humana, de un ámbito definido presuntamente como oscuro, sombrío y misterioso. Este ámbito puede considerarse como "anormal" y "abyecto" por parte de quienes, por ejemplo, legitiman el discurso normativo. Sin embargo, no solo es real en la experiencia humana sino también trascendental. No obstante, quienes se aferran a la norma y a una idea absoluta de verdad, (gozan de legitimidad) asocian este ámbito al mal. El lugar oscuro en donde residen los "monstruos" o los seres abyectos y anormales, constituye un espacio que confunde, perturba, corroe y violenta la normalidad, lo normal, normativo y legítimo. Según Foucault (1984), así funciona el poder sobre los "cuerpos débiles", los sujetos marginados y en desventaja en sociedad. Ellos son víctimas de quienes actúan con poder y protegen la normalidad a través de su discurso, un discurso justificado con legitimidad social y cultural.

En el caso del relato, las criaturas aladas simbolizan alegóricamente a quienes no siguen las prácticas "normalizadas" que promueve y privilegia el discurso legitimado. Por su supuesta anormalidad, estas criaturas deben ser vigiladas e invisibilizadas, en caso de que no puedan ser disciplinadas, enajenadas o "normalizadas" (Foucault, 1984). Estos monstruos, sin embargo, en el relato son indestructibles reforzando la idea que lo abyecto y anormal es parte de la condición humana. La ineludible presencia de la otredad de las cosas, como afirma Canguilhem (1976), de lo que pertenece a un orden distinto al orden probable constituye parte inherente de la condición humana. Asimismo, con cierto grado de ironía, el narrador relaciona a estos monstruos con el corazón del hombre: el corazón de un marino y las sombras que lo habitaban, el corazón del hombre de dientes roídos y el cabello blanqueado por el viento, que según el mismo era uno con los árboles. Lo considerado "otro", anormal, abyecto reside dentro del ser, como afirma Kristeva (1982), aunque, por conveniencia de algunos, se pretenda ignorar e invisibilizar.

Las voces que seducen al niño son las voces de la experiencia, las voces del conocimiento del bien y el mal que permitirían al niño sabser de otras subjetividades no normalizadas, de otras realidades diferentes, de otros mundos y nuevos horizontes; sobre todo si se toma en cuenta que el niño se desarrolla dentro de una sociedad en donde según Hernández (2007a, p. 8) "los niños no son de fiar". En el cuento, la madre del niño derriba las acacias para que el niño no terminara haciéndose a la mar como decía la abuela de la lavandera que sucedería; sin embargo, al final es el niño quien llama a los monstruos en la arboleda invisible de acacias. El texto sugiere que es el niño quien anhela aprender, ver la vida como es: oscura y clara, buena y mala, normal y anormal.

Una situación similar ocurre en el relato "Un nombre que es la oscuridad" (Hernández, 2007a, p. 6). Aquí también lo monstruoso está representado por la oscuridad. La oscuridad es una forma seductora masculina que "no es human[a]" y se pasea por entre los turistas en la plaza de la señoría. Esta forma también habla, fascina y seduce a una hermosa chica a la que conduce a explorar el mundo entero (Hernández, 2007a, p. 6). La oscuridad es 
una forma varonil apoteósica que funda la ciudad. La chica sigue su voz y acepta conocer con él lo concebido como abyecto, lo prohibido, lo que está escondido, lo que, según el cuento, es indecible, y lo que se ve más allá de la apariencia. La oscuridad en forma de hombre-dios introduce ambiguamente al personaje femenino dentro de un mundo imaginario anómalo y peligroso que, en forma figurativa, alberga lo que es considerado presuntamente malo: el pecado y lo errado pero que, al igual que al niño en el relato anterior, causa seducción y fascinación. La personificación de la oscuridad constituye una figura espectral y monstruosa que, a pesar de ser "anormal" y "abyecta" permite crear y generar vida en una ciudad. Este ser abyecto hombre-dios es quien puede suplir "portentosos" placeres dentro de la ciudad y dentro de la mujer. La chica accede a seguirle y "en cuatro cuadras, a veces caminando, a veces flotando, [el hombre] le muestra el mundo entero" (Hernández, 2007a, p. 6).

El texto hace una referencia figurativa a lo que significa la oscuridad, un lugar en donde emerge la seducción y la sexualidad. Es ahí en las sombras y tinieblas en donde se descubre la potencialidad que tienen hombre y mujer para generar placer y vida. El sexo en el texto adquiere interpretaciones ambivalentes: es una necesidad oscura, asociada al pecado, a lo prohibido y abyecto pero, a la vez, es una acción placentera y generadora de vida. Además, es el hombre, en forma de monstruo, quien la controla, él es quien seduce, enseña y controla a la mujer, y ella descubre el placer que existe en la "transgresión" que hay en descubrir la sexualidad femenina. ¿Critica el texto la oscuridad que envuelve a la sexualidad, sobre todo la femenina y lo instintivo en la mujer? ¿Será la oscuridad la representación del placer sexual visto como una transgresión? ¿Sugiere el relato que es la sexualidad un espacio para conocer y para aprender? Todas las interpretaciones son posibles por la ambivalencia que presenta la narración.

Sin embargo, la sugerencia más clara en el relato es que la oscuridad representa un reservorio de "revelación" y conocimiento de cosas vedadas socialmente, conductas consideradas tabús, como el sexo, pero necesarias para la subsistencia. La oscuridad es el espacio en donde se conciben las más intrigantes experiencias humanas que generan vida (como el sexo) pero que por estar vedadas o condicionadas para algunos, como para la mujer, por quienes dictan la normatividad, se vuelven anómalas, pecaminosas y perversas.

Otro caso semejante sucede en el relato "El bar de la calle Hudson” (Hernández, 2007a, p. 10). La trama transcurre en un bar lleno de monstruos y personajes fantasmas. Es un sitio con "olor a tiempo detenido" que alberga monstruos en forma de bestias que gruñen y devoran a sus visitantes. No obstante, en contraste y de manera también ambivalente, es un lugar que acoge a un mar que canta historias de luz y oscuridad. Sin embargo, según la compañera de Eva, la protagonista: "no existía tal bar puesto que no había una calle Hudson en esa ciudad" (Hernández, 2007a, p. 11). Eva es conducida en este fantasmagórico bar por una "presencia" monstruosa que la lleva hasta un "todo" por un camino serpenteante.

Por sus características, este bar citadino constituye un sitio simbólico de encuentro personal. Es un escenario ficticio dentro del cual los visitantes experimentan un encuentro personal, un auto-reconocimiento como si se estuvieran viendo ante un espejo: algunos ven en su reflejo a un monstruo que gruñe y otros, como Eva, ven una presencia luminosa que la lleva por un laberinto en el que se encuentra a sí misma y encuentra un alto grado de realización. Ella salió de ahí como una "sombra entre las sombras por la calle Hudson", una calle que, según el cuento, no existe. Puede interpretarse en este relato que el personaje de Eva se desdobla entre lo monstruoso y lo luminoso y ella encuentra auto-realización en la penumbra, en el lugar oscuro donde habitan los monstruos. Esta situación sugiere, una vez 
más, que el conocimiento emerge entre las sombras, en medio del ámbito considerado como abyecto y anormal.

Asimismo, Eva, por su nombre, podría ser simbólicamente la Eva del génesis que sigue el camino serpenteante que la conducirá a conocer qué es la luz y qué es la oscuridad, qué constituye el bien y qué constituye el mal. ¿Estará el texto aludiendo a la necesidad de Eva de obtener sabiduría y conocimiento en la oscuridad? De hecho, la experiencia en el bar fantasma es para Eva incierta, puesto que al final ella no es más que una sombra. Sin embargo, Eva encontró la libertad de elegir por dónde conducirse en la vida, puede optar transitar entre los monstruos o alejarse el inexistente bar de la calle Hudson. Al final, Eva, representante de la mujer, elige el camino del laberinto serpenteante que la lleva a reconocer su libertad y su auto-reconocimiento y realización.

Para concluir, los monstruos en estos relatos susurrando al oído del niño, de la chica y de Eva figurativamente representan las voces de los "anormales", de los "otros", de los seres abyectos y excluidos que se mueven en la "oscuridad". Son las voces de "monstruos" que habitan en escenarios prohibidos. Son los sujetos que por su condición apariencia y comportamiento diferente al normativo, alteran el orden normal y se les considera monstruosidades. Son las voces que muestran realidades abyectas para quienes gozan de poder y legitimidad y que ellos deben silenciar e invisibilizar. Sin embargo, los cuentos las representan, las hacen visibles aunque representen realidades incómodas. Son recordatorios de que hay que mirar a veces hacia abajo en donde habitan los "anormales" vistos como desvalidos, los subalternos discriminados y excluidos en la posmodernidad centroamericana (los pobres, las mujeres, los niños) en donde un total de 40 de cada 100 habitantes de la región viven en condiciones desventajadas. No solo son pobres, ubicados en el empleo informal, sin derechos laborales, sino que se encuentran excluidos de todos los sistemas y políticas sociales de los estados (Núñez, 2013). Ese 40\% de la población no alcanza la línea mínima de ingresos, no cuenta con salario mínimo, tiene poco acceso a la educación, a la seguridad social, a pensiones, es decir, están fuera de los beneficios del desarrollo (Núñez, 2013). Y estos problemas sociales no vienen solos, ya que la desigualdad se traduce en situaciones de criminalidad y violencia, una situación que ha generado que la región sea catalogada como la más violenta del mundo (Núñez, 2013). En donde la violencia es parte constitutiva de la cultura. Estos son los nuevos "monstruos" de la posmodernidad centroamericana.

\section{Notas}

1. Reemtsa (2008) define varios tipos de violencia: la violencia locativa, aquella en donde los cuerpos se expulsan de los espacios que ocupan violentamente; la violencia captiva, en donde los cuerpos son retenidos en contra de la voluntad; la violencia raptiva, cuyas expresiones tienen que ver con la posesión abrupta del cuerpo para fines sexuales y la autotélica en donde la violencia es un fin en sí misma; es decir, cuando se destruye un cuerpo con el único fin de destruirlo.

2. De acuerdo con Kristeva (1982, p. 28): En un mundo en el que el Otro se ha derrumbado, el esfuerzo estético -descenso a los fundamentos del edificio simbólico- consiste en volver a trazar las frágiles fronteras del ser hablante lo más cerca posible de sus comienzos, de ese "origen" sin fondo que es la represión llamada primaria. Sin embargo, en esta experiencia sostenida por el Otro, "sujeto" y "objeto" se rechazan, se enfrentan, se desploman y vuelven a empezar, inseparables, contaminados, condenados, en el límite de lo asimilable, de lo pensable: abyectos. Sobre este terreno se despliega la gran literatura moderna. 


\section{Bibliografía}

Canguilhem, G. (1976). La monstruosidad y lo monstruoso. El conocimiento de la vida. (3347) http://es.scribd.com/doc/142312025/Canguilhem-Georges-Lo-monstruosidad-y-lomonstruoso-pdf/ [Consulta 26 de agosoto de 2014].

Cortez, B. (2010). Estética del Cinismo Pasión y desencanto en la literatura centroamericana de posguerra. Guatemala: F\&G Editores.

Chevalier, J. (1995). Diccionario de símbolos de Jean Chevalier. Por M. Sivar y A. Rodríguez (Eds.). Barcelona: Editorial Herder.

Christie, B. (2014, 31 de mayo). The Egyptians Had Their Own Version Of Ayahuasca They Called "The Tree Of Life". http://www.collective-evolution.com/2014/05/31/the-treeof-life-acacia-nilotica/ [Consulta 26 de agosto de 2014].

Foucault, M. (1984). Michel Foucault. Dictionaire des philosophes. (Vol. 1). (941-944). Paris: PUB. https://inecipcba.files.wordpress.com/2013/05/autorretrato-maurice-florence.pdf [Consulta 26 de agosto de 2014].

Foucault, M. (2003). El Poder Psiquiátrico. Curso en el Collège de France (1973-1974). [pdf]. http://monoskop.org/images/8/80/Foucault_Michel_El_poder_psiquiatrico.pdf [Consulta 26 de agosto de 2014].

Foucault, M. (2007). Los anormales. Buenos Aires: Fondo de Cultura Económica.

Hernández, C. (2007a). La canción del mar. (obra inédita).

Hernández, C. (2007b). De Fronteras. Guatemala: Piedra Santa.

Kristeva, J. (1982). Powers of Horror: An Essay on Abjection. NY: Columbia University Press.

Mackenbach, W. (2004). Después de los pos-ismos: ¿desde qué categorías pensamos las literaturas centroamericanas contemporáneas? Istmo Revista virtual de estudios literarios y culturales centroamericanos. 8. http://istmo.denison.edu/n08/articulos/ pos_ismos.html [Consulta 26 de agosto de 2014].

Núñez, M. J. (2013, 31 de julio). Informe Estado de la Región: Un 40\% de centroamericanos son excluidos del desarrollo. Semanario Universidad. http://www.semanariouniversidad. ucr.cr/noticias/pais/10910-informe-estado-de-la-region-un-40-de-centroamericanosson-excluidos-del-desarrollo.html/ [Consulta 26 de agosto de 2014].

Ortiz-Wallner, A. (2008). La problemática de la periodización de las literaturas centroamericanas contemporáneas. Intersecciones y transgresiones: Propuestas para una historiografía literaria en Centroamérica I. (183-204). Guatemala: F\&G Editores.

Pérez, Y. (2012). El poder de la abyección y la ficción de posguerra. Perversiones de la modernidad. Literaturas, identidades y desplazamientos III. (50-52). Guatemala: F\&G Editores.

Reemtsma, J. P. (2008). Vertrauen and Gewalt. Versuch uber eine besondere Konstellation der Moderne. Hamburgo: Hamburger Edition. 
